than to accelerate the country's economy, and it is therefore proposed that research on a far larger scale must be supported on the biological and medical aspects of human reproduction so that improved methods of fertility control can be developed. In 1965 an estimated $\$ 13,027,446$ was being spent on sterility, fertility and population dynamies.

\section{Poor Laws for the Rich}

LOCAL authorities in Britain administer between them some 3,000 different means tests to would-be beneficiaries of assistance schemes. Mr Mike Reddin of the London School of Economics has established by experiment that the multiplicity of these means tests ensures a wide range of variation in the assistance that different local authorities will award to the same individual (Falian Tract 382: Social Services for All?).

Local authorities were asked to state the benefits they would grant to a series of hypothetical families, constituted so as to be eligible for all the major means tested services. One such family consisted of a mother and father and four children, all in full-time cducation, aged $8,11,16$ and 18 . The range of variation (see table) is such that in every case it is entirely possible

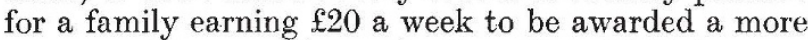
generous allowance than a family with half this income.

Anomalies of this sort are one result of the plethora of means tests; another is the unnecessary administrative effort in applying so unstandardized a system. Perhaps the most serious evil of the situation is that its sheer complexity probably leaves many people in ignorance of the benefits to which they are entitled. Mr Reddin notes that each scheme must be effectively publicized if it is to be fully used, but such publicity is non-existent.

VARIATION IN BENEFTTS AWARDED BY LOCAL ALTHORITIES TO FAMULIES WI'TH FOUR CHILDREN OF SCIOOL AGE

\begin{tabular}{|c|c|c|c|}
\hline & $\begin{array}{l}\text { Annual grant } \\
\text { for education } \\
\text { of second child }\end{array}$ & $\begin{array}{l}\text { Rent rcbate } \\
\text { for three- } \\
\text { bedroom } \\
\text { house }\end{array}$ & $\begin{array}{c}\text { Charge } \\
\text { for } \\
\text { domestic } \\
\text { help for } \\
20 \mathrm{~h} / \text { weel }\end{array}$ \\
\hline $\begin{array}{l}\text { Family A } \\
\text { (income } £ \text { l]0/week) }\end{array}$ & $£ 40$ to $£ 115$ & nil to $84 \%$ & nil to $£ 2 \frac{1}{2}$ \\
\hline $\begin{array}{l}\text { Family B } \\
\text { (income } f 15 / \text { week) }\end{array}$ & nil to $£ 105$ & nil to $56 \%$ & nil to $£ \tilde{~}$ \\
\hline $\begin{array}{l}\text { Family C } \\
\text { (income } £ 20 / \text { week) }\end{array}$ & nil to $£ 65$ & nil to $26 \%$ & 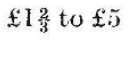 \\
\hline
\end{tabular}

In the same publication Mr Peter Kaim-Caudle of the University of Durham calculates the value of aid for each child of parents in various income groups. The length of a child's full-time education is directly proportional to parental income, which means that the better off benefit more from state aid than do the less well off. Throughout each child's period of dependency,

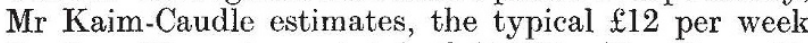
family will receive a total of $£ 1,800$. Families with incomes of $£ 24, £ 36$ and $£ 72$ per week will receive totals of $£ 3,200, £ 7,000$ and $£ 4,400$ respectively.

These extraordinary findings will add fuel to the arguments about selectivity in the social services. Memories of the thirties, when a notorious means test was operated, have always counted for a good deal within the British Labour Party; but this evidence gathered by the Fabians is bourd to suggest that selectivity is not only wrong but inefficient as well.
Certainly $\mathrm{Mr}$ Kenneth Robinson, the Minister of Health, who has been wrestling with the problem of re-imposing prescription charges except for a few favoured categories of patient, will confirm that arrangements of this kind are in practice very hard to operate.

Peter Kaim-Caudle also argues that the effect of selectivity is to reduce incentives for low wage earners even more substantially than progressive taxation policies do for the salary earner. He points out that an average married couple with two children lose $3 s .4 d$. rent rebate for every $£ 1$ by which their income rises between $£ 16$ and $£ 20$. In addition, the same family may lose $5 s$. rates rebate for every $£ 1$ increase in wages, and when earnings exceed $£ 1510 \mathrm{~s}$. their children lose their free school meals. The increase in graduated pension contribution is added to this. For an earnings increase from $£ 15$ to $£ 18$, the family lose $15 s$. worth of school meals, $13 s .4 d$. in rent rebate, $15 s$. in rate rebate, and $2 s .10 d$. in graduated pension contribution. From the extra $60 s$. a week, $46 s$. $2 d$. is therefore swallowed up, equivalent to $15 s .4 d$. in the pound.

This, no doubt, is an extreme example, but it does illustrate that selectivity is a two-edged weapon, to be used with great caution, if at all. As Mr KaimCaudle concludes, the discouragement for the low wage earner by loss of benefit is almost certainly greater than it is for the middle class executive.

\section{Examinations for Programmers}

The case of the private computer schools was aired in the House of Commons last Friday, May 31. It was clear that the Minister of State for the Department of Education and Science, Mrs Shirley Williams, was fully aware of the disturbing state of affairs in some schools. Mrs Williams, in fact, conceded a great deal of the case. Replying to a debate begun by Mr John Hunt (MP for Bromley), Mrs Williams said that the "aptitude tests offered to people who wish to attend private computer schools are in many cases worthless as any effective form of selection". She went on to say that "the courses in many cases, although not in all, do not lead to recognized national examination standards, and in some cases, although students may take such an examination, the syllabus they followed gives little chance of their getting satisfactorily through it". A number of schools are tempted to accept unsatisfactory students because of the "large sums of money spent"some schools' fees were as high as $£ 150$ for a six-week course.

It was made clear in the debate that there is little that the department could do to prevent students applying to unsatisfactory schools, although it could encourage schools to apply to the department for recognition as "efficient". The department could, however, publicize the merits of other alternative courses. A new booklet published jointly by the department and the Central Office of Information gives guidance to students about recognized training courses, and details of examinations set and administered by bodies like the City and Guilds and the British Computer Society. The British Computer Society has now at last become a professional body with its own examinations. The plan to do so, put forward in June 1967, was approved at the extraordinary general meeting on 
March 25. Examinations in computing science leading to membership qualifications are to be introduced in 1969 but, to begin with, the qualifying requirement will be based on age and computing experience. A spokesman for the society said this week that the qualifying examinations would be on the level of a BSc honours degree in computing science.

Overall co-ordination of recognized computer courses is to be undertaken by a new committee, the Coordinating Committee for Examinations in Computing Studies. This committee, said Mrs Williams, "is allocating courses among its constituent members, and is trying to establish nationally recognized examinations ... . but we cannot give any absolute guarantee that this will happen". The committee cannot force private schools to follow syllabuses leading to these examinations, but it is hoped that those that do will "drive out the bad".

A second committee will also help to inform prospective students about recognized training courses. Known as the Computer Training Policy Subcommittee, it has been established by the Engineering Industry Training Board with representatives from the DES, the main computing manufacturers, the National Computing Centre and from the new co-ordinating committee.

\section{Optics Applied}

THE applied optics section at Imperial College, a postgraduate section of the Department of Physies, was set up towards the end of the First World War to improve the poor quality of the optical instruments used by the British forces, and is this year celebrating its jubilee. At an open day to mark the event, the wide variety of research now bsing undertaken in the section's laboratories was exhibited. This work includes an investigation of the lighting of picture galleries, various aspects of the physics of vision, colour measurement, holography and optical design. It is the optical design group, set up as an experiment 7 years ago by the forerunner of the Science Research Council, which recently has been particularly successful. The group is concerned with improving the performance of existing lens designs, and developing new lens systems, and has pioneered the use of computers to carry out the tedious calculations involved.

The group is making its name in telescope optics by designing lens systems to correct an aberration known as coma, a defect common in large astronomical telescopes. Coma is one of the penalties paid for keeping astronomical telescopes as short as possible to cut down the cost of the dome which houses them. The group has designed corrector lenses for a number of telescopes, including the 200 in. on Mount Palomar and the Isaac Newton telescope.

Sophisticated lens systems are also needed in high energy nuclear physics, for bubble chamber photography. The optical design group has assisted with the optics of a number of bubble chambers including one at Brookhaven National Laboratory. An automatic scanner is now being developed to speed up the analysis of stereoscopic photographs of bubble chamber tracks. The applied optics section at Imperial College is also working on the illumination of large bubble chambers, in the region of 4 metres in diameter. To make full use of these large chambers, an optical system with a good depth of focus is needed. Holographic techniques are being developed using an optical system arranged so that the central plane of the chamber is in focus. A photograph will then include focused images of tracks in the central plane together with holograms of the out-of-focus tracks, which enable the locations of the out-of-focus tracks to be measured.

\section{Seeing Round Corners}

THE basis of fibre optics is that light is transmitted along narrow fibres of glass, coated with a material of lower refractive index, by multiple internal reflexions. Light thus follows the path of the fibre, so long as the curvature of the fibre is not so great that the angle of incidence of the light inside the fibre exceeds the critical angle. Typically, the thickness of the fibres is between $0.01 \mathrm{~mm}$ and $0.1 \mathrm{~mm}$. For all practical purposes they are bunched together, in various ways depending on the application, so that each fibre transmits light from one end of the bundle to the other.

The development of this simple idea has been slow, chiefly because of manufacturing problems to do with the coating of the individual fibres and production of the bundles. These commercial obstacles are beginning to be overcome, however, and devices incorporating fibre optics are appearing on the market. Basically there are two ways of arranging the fibres to make up a fibre optic device. In a so-called coherent device the relative positions of the fibres are the same at each end of the bundle, so that an image at one end of the device is faithfully reproduced at the other end. The resolution depends on the thickness of the fibres. On the other hand, the fibres in a non-coherent bundle are bunched together at random and so cannot transmit an image. Because the relative positions of the fibres in coherent devices have to be maintained at both ends of the bundle, their cost is greater than for noncoherent bundles of the same size and wherever possible non-coherent devices are used.

It is not difficult to think of applications for fibre optics. For instance, devices incorporating coherent bundles are already available for viewing inaccessible places, the illumination provided via a non-coherent bundle. In conjunction with photo-electric cells fibre optics can be used to construct instruments as diverse as burglar alarms, punched card readers, illuminated display panels and fire detectors. Bundles of fibres can be fused together to form rigid rods, transmitting light in the same way as the flexible bundles. By drawing out one end of a rigid coherent rod, a cone of fibres which will produce a magnified or reduced image is formed. A $180^{\circ}$ twist in a coherent rod is a simple way of accomplishing image reversal.

Many applications of fibre optics which have been put forward are only fractionally simpler ways of carrying out tasks which are now being done by electrical and optical systems. The question is whether the advantages of fibre optics are sufficient to make their introduction worth while. Medical and dental applications of fibre optics are a different matter, however. The chief advantage here seems to be in the provision of cold light sources, as the fibres do not transfer the heat from the initial light source to the object being viewed. For example, deep tissue can be illuminated by a non-coherent fibre optic the size of a large hypodermic needle, the tissue being viewed by a second coherent fibre optic connected to a microscope. 